\title{
La perífrasis soler + INFINITIVO a la luz del latín (I): Soleo, el origen latino del auxiliar soler
}

\author{
Laura Cabré Lunas ${ }^{1}$ \\ Universitat de Barcelona, España
}

\begin{abstract}
Resumen
Este trabajo se centra en la descripción del verbo soleo, cognado latino del auxiliar soler, con el objetivo de contribuir al esclarecimiento de la perífrasis léxica del español soler + INF, al considerarla desde una perspectiva diacrónica. Soleo es un verbo insólito cuya singularidad se manifiesta en su etimología y en sus particularidades gramaticales. Sobre su etimología se han barajado dos hipótesis que parten de dos temas de Aktionsart distintos: una lo hace derivar de un tema iterativo protoindoeuropeo, la otra, de un tema estativo. A partir de esta segunda hipótesis etimológica cabría incluirlo entre los presentes estativos denominativos latinos, con la acepción básica de 'ser de uno, tener como propio, ser normal, ser costumbre'. En cuanto a sus particularidades morfosintácticas, el semideponente soleo presenta un tema de perfecto morfológicamente pasivo, solitus sum, cuyo uso con valor aorístico entra en contradicción con la restricción morfológica del auxiliar español soler y con la categorización aspectual de auxiliar habitual que se le atribuye. Junto al funcionamiento como verbo auxiliar constituyendo una perífrasis con infinitivo, presenta también un empleo como verbo léxico pleno en el que aflora el valor semántico prototípico de su etimología.
\end{abstract}

\footnotetext{
Para correspondencia, dirigirse a: 1cabre@ub.edu. Departamento de Filología Clásica, Románica y Semítica. Facultad de Filología de la Universitat de Barcelona, Gran Via de les Corts Catalanes, 585, 08007 Barcelona. Tel. +34 (93) 4035598.
} 
Palabras clave: latín, soleo, etimología, verbo semideponente, verbo léxico pleno, verbo auxiliar, soler + INF.

THE PERIPHRASIS SOLER + INF IN THE LIGHT OF LATIN (I): Soleo, the Latin origin of the Spanish auxiliary soler

Abstract: This paper focuses on the description of the verb soleo, the Latin cognate of the Spanish auxiliary soler, with the aim of contributing to the explanation of the Spanish lexical periphrasis soler + INF, when considering it from a diachronic perspective. Soleo is an especial verb whose singularity is manifested in its etymology and its grammatical particularities. Concerning its etymology, two hypotheses have been considered which start from two different Aktionsart stems: one makes it derive from a ProtoIndo-European iterative stem, the other from a stative one. From this second etymological hypothesis, soleo could be included among Latin denominative stative $* \bar{e}$-presents with the basic meaning of 'to be of oneself, to have as one's own, to be normal, to be custom'. Regarding its morphosyntactic features, the semi-deponent soleo has a morphologically passive perfect stem, solitus sum, whose use with aoristic value comes into contradiction with the morphological restriction of the Spanish auxiliary soler and with the aspectual categorization of habitual auxiliary attributed to it. Together with the function as an auxiliary verb constituting a periphrasis with an infinitive, it also presents a use as a full lexical verb in which the prototypical semantic value of its etymology emerges.

Keywords: latin, soleo, etymology, semi-deponent, full lexical verb, auxiliary verb, soler + INF.

Recibido: 08/06/19

Aceptado: 11/08/19 


\section{INTRODUCCIÓN²}

En el proceso de gramaticalización de una perífrasis verbal, Squartini (1998: 2) señala el papel fundamental de la interacción entre dos factores básicos: el aspecto, entendido tradicionalmente como categoría gramatical, relacionado con la morfología y la sintaxis, y la Aktionsart o modo de acción, en tanto que categoría léxica. Destaca, asimismo, la importancia de otro principio determinante en el proceso de gramaticalización establecido por Hopper (1991: 28), el de la persistencia en mayor o menor medida del valor semántico original conservado por el elemento léxico en su proceso de transformación de unidad léxica independiente en morfema flexivo. Según este principio, incluso un morfema fuertemente gramaticalizado retiene algo del significado léxico original.

La gramática de construcciones en un enfoque diacrónico pretende dar cuenta, por una parte, de la construccionalización, esto es, del proceso de constitución de construcciones nuevas a partir de la asociación de una nueva forma con un nuevo significado, y, por otra, del cambio construccional, es decir, de la modificación o bien de la forma, o bien del significado de una construcción en particular (vid. Traugott y Trousdale 2013, así como la breve referencia contenida en la introducción de este monográfico). Por lo que atañe a las perífrasis verbales, como sostiene Garachana (2017: 56), conviene subrayar que, en estructuras como estas, en las que:

dos verbos se combinan para expresar un nuevo significado, se ha producido un proceso de gramaticalización que ha llevado a la aparición de una nueva construcción verbal, cuyo significado, no composicional, puede conservar trazas de los significados etimológicos de la construcción, que dejan su impronta en el significado de la perífrasis al completo.

Partiendo de estas consideraciones, en el presente trabajo ofreceremos una descripción del verbo latino soleo, antecedente del auxiliar soler, con el objetivo de contribuir al esclarecimiento del patrón evolutivo de la construcción soler + INF en español.

En primer lugar, para conocer la Aktionsart subyacente en la semántica de soleo examinaremos las explicaciones etimológicas que se han propuesto. A

\footnotetext{
Agradezco al Dr. Tomeu Obrador y a la Dra. Mariona Vernet, profesores de la sección de Filología latina y Lingüística indoeuropea del Departamento de Filología Clásica, Románica y Semítica de la Universitat de Barcelona, sus atinadas observaciones y el contraste de información para el apartado de la etimología de soleo.
} 
continuación, el análisis de sus particularidades morfológicas y de sus usos sintácticos nos aportará información de carácter aspectual para ser contrastada con soler. Como se verá, el rasgo común a todos los contextos en los que opera el verbo latino soleo, formación atestiguada desde la latinidad más temprana, es que se trata de una rara avis, de un verbo "insólito" y singular. Sin parangón en el ámbito de las lenguas indoeuropeas como formación verbal, dentro del paradigma morfológico del verbo latino, forma parte del peculiar y reducido grupo de los semideponentes. Por lo que se refiere a su funcionamiento sintáctico, se incluye entre los pocos verbos auxiliares indiscutibles, como representante del valor aspectual de habitualidad, pero manifiesta un funcionamiento como verbo pleno, documentado desde los usos más antiguos, que no puede ser soslayado.

El trabajo se subdivide en tres secciones. La primera sección está dedicada a la etimología de soleo. En la segunda sección se abordan sus particularidades morfosintácticas. Concretamente se exponen, en apartados independientes, las restricciones morfológicas y los usos sintácticos del verbo. La tercera y última sección constituye una breve recapitulación de los datos aportados para su contraste con el funcionamiento del auxiliar español soler.

Los ejemplos han sido extraídos de los corpus documentales latinos consignados en la bibliografía. En cuanto a su traducción, es importante indicar que es propia y que cumple un objetivo, por encima de todo, instrumental, cuya única pretensión es ilustrar nuestros planteamientos. En muchos casos hemos aplicado, como criterio básico, la fidelidad a la estructura original, aun a riesgo de incurrir en enunciados anómalos para la gramática del español, que hemos señalado oportunamente con un asterisco.

\section{SOBRE LA ETIMOLOGÍA DE LAT. SOLEO}

En el contexto de las lenguas indoeuropeas no existe un verbo equivalente al latino soleo. Parece que se trata de una formación aislada, sin explicación etimológica clara, que incluso algún investigador se aventura a calificar de probable reliquia arcaica del latín (Hamp 1985: 16).

Las opciones que se han barajado para explicar la etimología del verbo latino soleo pueden resumirse en dos hipótesis: una que lo relaciona con el gótico saljan, 'permanecer, alojarse' y con el sustantivo latino solum (n.), 'suelo'; y otra que lo emparenta con el verbo incoativo lat. suesco, 'me acostumbro' y con el sustantivo lat. sodalis (m.), 'cofrade, camarada'. 
Un factor muy importante es el hecho de que cada una de estas hipótesis asume como base de la formación un tema de Aktionsart de distinta naturaleza ${ }^{3}$, -la primera, un tema iterativo, la segunda, un tema estativo-, lo cual determinaría la semántica y la sintaxis del verbo que nos ocupa, así como la naturaleza aspectual de la perífrasis que constituye.

\subsection{SOLEO $<*_{\text {SOL-ÉYE- }}<*_{\text {SEL- }}$}

En el Lexikon der indogermanischen Verben (LIV) de Helmut Rix (20012: 528) se hace derivar de la raíz verbal protoindoeuropea (PIE) *sel- 'vivir, alojarse' un tema iterativo PIE *sol-éye que documentarían los verbos lat. soleo y gót. saljam. Sobre esta misma raíz *sel-, además, se habrían formado los sustantivos lat. solum (n.) 'base, suelo', antiguo alto alemán $s \bar{a} l(\mathrm{~m}$. 'habitación, sala', antiguo eslavo eclesiástico selo (n.) 'terreno, pueblo'. En este sentido, el LIV da validez y asume una vieja teoría de Grienberger (1900: 180) que comparaba lat. soleo con gót. saljan. Cabe señalar, sin embargo, que la relación entre los dos verbos ha sido puesta en entredicho por Lehmann (1986: 294) desde el estudio de la forma gótica.

Vernet (2008: 494) halla satisfactoria la propuesta postulada en el LIV de hacer derivar un tema iterativo PIE *sol-éye, -que atestiguarían lat. soleo y gót. saljan-, a partir de la raíz * sel-, sin más cognados verbales que estos, pero conservada en sustantivos como lat. solum. Por consiguiente, en su estudio etimológico y comparativo sobre el origen PIE de la formación de los temas verbales de la segunda conjugación latina, Vernet (2008: 588) incluye soleo dentro de la categoría de verbos provenientes de un tema iterativo PIE.

De Vaan (2008: 570-571), por su parte, en el Etimological Dictionary of Latin (EDL) también considera verosímil la relación entre soleo y los derivados nominales lat. solum, aaa. sāl y aeslec. selo. A partir de aquí supone que, o tenemos una raíz verbal PIE con el sentido de 'ocupar, habitar', de la que derivarían los sustantivos mencionados y el verbo latino, -que representaría una formación de Aktionsart iterativa con vocalismo radical *o y sufijo temático *-éye-, interpretable como 'ocupar habitualmente'; o soleo es una creación latina derivada de solum que habría significado 'estar

\footnotetext{
Una exposición extensa y detallada sobre el paradigma verbal protoindoeuropeo y su evolución hasta el paradigma verbal latino puede leerse en Vernet (2008: 3-70). Cf. también la síntesis de Haverling (2010: 279-283) sobre los antecedentes indoeuropeos del sistema verbal del latín.
} 
ocupado, habitado' y, secundariamente, 'estar habituado'. Si se acepta la primera posibilidad, soleo constituiría una construcción verbal interna latina sin ningún otro paralelo verbal en una lengua indoeuropea, más allá del cuestionado got. saljan; si, en cambio, entendemos que soleo procede del sustantivo latino solum, se trataría de una formación verbal estativa secundaria, que habría que incluir en el total de los ocho verbos esivos de origen secundario provenientes de un sustantivo latino, contabilizados por Vernet (2008: 597) para la segunda conjugación latina.

\subsection{SOLEO $<*^{*} W E D^{H} H_{1}-E H_{I} Y E-$}

La segunda hipótesis de explicación etimológica es la que relaciona soleo con sodalis y con suesco. Como señala de Vaan (2008: 571), semánticamente nuestro verbo está más cerca de suesco, 'me acostumbro' y de sodalis 'cofrade, camarada'. Desde el punto de vista formal, sin embargo, este parentesco etimológico plantea algunos inconvenientes que se han objetado a quienes lo defienden.

Pokorny (1959-1969: 883) se encuentra entre los defensores de esta hipótesis. En su Indogermanisches etymologisches Wörterbuch (IEW) emparenta soleo con sodalis $\left({ }^{*}\right.$ swed ${ }^{h} \bar{a}$ lis $)$ y suesco $\left({ }^{*} s w e d^{h}-s k \bar{o}\right)$ partiendo de una raíz verbal PIE *swedh-. Se trata de la raíz de ved. svadha 'idiosincrasia, costumbre” y de gr. "̌́ $\theta$ o ` 'costumbre' (participio Homérico ह̌ $\theta \omega v$ 'habitual, acostumbrado'; perf. elí $\omega \theta \alpha$ 'ser habitual').

Con respecto a esta etimología, de Vaan (2008: 571) plantea dos reparos formales. Por una parte, para llegar a soleo, ${ }^{*}$ swed ${ }^{h}-\bar{e}->*^{*}$ sode- tiene que experimentar un desarrollo irregular de la intervocálica $* d$ a $l$. Por otra parte, de Vaan afirma que el tratamiento vocálico *swe- $>$ so- se vería impedido por la vocal larga siguiente $\bar{e}$ y esto lo lleva a rechazar definitivamente la propuesta etimológica de Pokorny. La particularidad que supone la conmutación fonética de $d$ a $l$ no tiene mayor trascendencia. Hay otras formas que atestiguan en latín el cambio de intervocálica $* d>l$ : odor (gr. ó $\delta \mu \eta$ ) 'olor', odorari (gr. ő $\zeta \omega)$ 'oler' frente a las variantes olor 'olor', oleere 'oler'4; solium 'sitial, trono' frente a sedere 'sentarse'; o bien Ulixes 'Ulises'

4 Esta particularidad fonética no pasó desapercibida a los antiguos ( $c f$. Varro, De lingua latina 6, 83: Littera commutatat dicitur odor olor, hinc olet et odorari). Algunos especialistas han atribuido la responsabilidad del fenómeno a la influencia dialectal sabina, conocido, por ello, como labdacismo sabino, pero no parece que haya argumentos sólidos para apoyar esta teoría sobre el origen de la commutatio entre $d$ y $l$ (Poucet 1966: 148). 


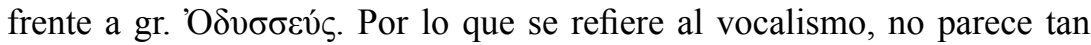
insalvable como asegura de Vaan (2008: 571): presentaría un tratamiento análogo al de sodalis, que el propio de Vaan considera derivado de la raíz PIE *swe-d $h_{1} h_{1}$ (2008: 570).

En el Lexikon der indogermanischen Partikeln und Pronominalstämme (LIPP), posterior al EDL, Dunkel (2014: 760) analiza la raíz $*_{s w e}{ }^{h} h_{I^{-}}$ 'particularidad, costumbre; domicilio' de IEW (883), a partir de *swe- $\varnothing$ $d^{h} h_{l^{-}}$'determinar, definir por sí mismo', compuesto verbal cuyo primer término es el radical pronominal *swe- del reflexivo ${ }^{5}$. Asocia a esta misma raíz el protoindoiranio *swad ${ }^{h} H$ - (f.) 'idiosincrasia, carácter', atestiguado en ved. svadhā; y relaciona, asimismo, con ella, gr. $\ddot{c} \theta o \varsigma$ y lat. suodālis, sodālis, soleō.

Si partimos de esta hipótesis etimológica para el verbo solère, aceptada sin reservas en léxicos recientes como el LIPP de Dunkel, podríamos considerarlo una formación alargada con el sufijo $*_{-}-\bar{e}_{-}<*_{-}$éh $h_{1} e_{-}$, de Aktionsart estativa o esiva, que denota el "estado o condición del sujeto, sin énfasis en la entrada en tal estado o condición, a diferencia del perfecto" (LIV: 25) ${ }^{6}$. Cabría contarlo, pues, entre los presentes estativos denominativos en $*_{-} \bar{e}$ - de la segunda conjugación latina ${ }^{7}$ y atribuirle como acepción básica la de "ser de uno, ser propio, ser normal, ser costumbre".

\section{PARTICULARIDADES MORFOSINTÁCTICAS DE LAT. SOLEO}

Soleo, solère, solitus sum [1 (con inf.) 'soler, acostumbrar, tener la costumbre'; 2 (con inf. elipt.) 'soler'; (con prep. cum o ac. de pers.) 'tener

Hamp (1985:16) también considera soleo como derivativo de * swe-, aunque su propuesta de reconstrucción fonológica * sweleyō estaría formada sobre un supuesto sustantivo temático * swelo-; este, por su parte, sería una tematización de un también supuesto genitivo antiguo *swe-l 'de uno mismo, propio de uno'. Según Hamp, el sentido original de soleō habría sido 'tener como propio'.

${ }^{6}$ Estas formaciones, como señala García Trabazo (2004: 105), corresponden a lo que tradicionalmente se conocía como 'presentes de estado' o 'estativos' en *-ē-.

7 Acaso habría que incluirlo entre los verbos de la segunda conjugación latina que Vernet (2008: 591) clasifica bajo el epígrafe de "Verbs essius provinents d'un tema essiu pie. però que l'arrel verbal pie. té un origen denominatiu". La relación solēre 'ser costumbre': suēscere 'acostumbrarse' podría ser analógica a la de albēre 'ser blanco': albēscere 'emblanquecerse'; esto es, de presente estativo denominativo a formación deverbativa incoativa. 
trato, tratar'; 3 (expr. frecuencia de acción o experiencia) 'ser propenso, apto'; 4 (con pronombre neutro como sujeto) 'ser habitual, propio, típico' $]^{8}$ es un verbo empleado con frecuencia en todas las épocas de la latinidad y, muy especialmente, en época arcaica, en la que casi están atestiguados todos sus significados (Vernet 2008: 493).

Se trata de un verbo de la segunda conjugación latina, grupo constituido por una amalgama de formaciones verbales de origen y morfología diversos, con vocalismo temático $-\bar{e}$. La gramática tradicional establece para esta compleja conjugación cuatro clases de verbos, atendiendo al origen de su tema de presente (Leumann 19775: 540-542): a) verbos radicales en $-\bar{e}$; b) verbos causativos e intensivos / iterativos; c) estativos deverbativos; $y$ d) estativos denominativos intransitivos. Como acabamos de proponer, si damos por buena la hipótesis de explicación etimológica más recientemente adoptada, soleo debería adscribirse a esta última clase de verbos estativos denominativos intransitivos.

Por otra parte, junto a audeo 'ser audaz; osar', gaudeo 'estar contento, gozar' y fido 'fiarse, tener confianza', soleo constituye el reducido grupo de verbos denominados semideponentes. Flobert (1975: 496) señala que entran dentro de esta categoría aquellos verbos que integran como participio en su paradigma activo un adjetivo verbal en -tus, procedente de un adjetivo primitivo en -*to-, que les proporciona el tema de perfectum. El adjetivo verbal en - *to- marcaba el proceso como llegado a su realización completa y suponía un estado definitivo que se prestaba a su materialización como una cualidad permanente. En latín, este adjetivo verbal primitivo proporcionó el participio perfecto pasivo; las formas verbales del perfectum pasivo se construyeron mediante una perífrasis constituida precisamente por el participio en -tus y el auxiliar sum. Así pues, los verbos semideponentes se caracterizan por presentar como anomalía morfológica un tema de infectum activo (audeo, gaudeo, fido, soleo) asociado a un tema de perfectum pasivo (ausus sum, gavisus sum, fisus sum, solitus sum), de comportamiento activo.

Los gramáticos antiguos etiquetaron estos verbos como neutropassiva, anomala, inaequalia, defectiva o supina ${ }^{9}$ y se limitaron o bien a señalar

Cf. OLD, s.u. soleo.

Para Flobert (1975: 496) la denominación de supina sería la más apropiada. Se trata de un término ligado a la teoría gramatical antigua del genus (concepto complejo en el que se mezclan criterios semánticos y morfosintácticos y se confunde la distinción actual entre voz y diátesis); dentro del genus neutrum, constituido por verbos únicamente de forma activa que pueden tener un sentido activo o pasivo, la determinación de supinum se usa para designar la subclase de sentido pasivo (como vapulo ‘ser azotado' o veneo ‘ser vendido'). Para un análisis 
el vínculo morfológico con la voz pasiva, o bien a evidenciar el carácter irregular de su flexión.

\subsection{RESTRICCIONES MORFOLÓGICAS}

Respecto al paradigma morfológico del semideponente latino soleo conviene abundar en algunos datos para contrastarlos con las importantes restricciones que en este ámbito manifiesta el defectivo soler del español. Como referencia, partimos de la información que nos ofrece el gramático latino Flavio Sosípater Carisio (s. IV):

(1) Charis. GL I 249, 10: DE DEFECTIVIS. Sunt quedam verba quae ex forma agendi in passivum perfecto vertuntur, quae etiam defectiva appellantur, secundi ordinis, velut soleo soles solitus sum (...); GL I 249, 13: sed soleo verbum futurum omnino non habet, quia vim habet praeteriti nec potest aliquis futuris consuesse (...). GL I 325, 15 : Declinantur autem praedicta verba hoc modo. Secundi ordinis finitiva instantis soleo soles solet; inperfecti solebam solebas solebat; perfecti solitus sum, plusquamperfecti solitus eram, futuri solebo. Imperativa instantis sole, futuri solitus esto. Optativa instantis et inperfecti $<$ ut $>$ solerem, perfecti ut solitus sim, plusquamperfecti ut solitus essem, futuri ut soleam. Subiunctiva instantis cum soleam, inperfecti cum solerem, perfecti cum solitus sim, plusquamperfecti cum solitus essem, futuri cum solitus ero. Infinita instantis solere, perfecti et plusquamperfecti solitum esse et fuisse, futuri solitum iri vel soliturum esse. Participia instantis hic solens $<$ et cetera $>$, perfecti hic solitus $<$ et cetera $>$, futuri $<$ hic $>$ soliturus et cetera. Huius verbi quamvis futura declinata sint, tamen dici non possunt, quia praeteritis, non futuris, potest aliquis consuesse, ita ut superius memoratum est.

'SOBRE LOS DEFECTIVOS. Hay algunos verbos que cambian de la forma activa a la pasiva para el perfecto, que también se llaman defectivos; los hay de la segunda conjugación, como soleo, soles, solitus sum (...); pero soleo no tiene ninguna forma verbal de futuro porque tiene valor de pasado y nadie puede estar acostumbrado a

específico sobre el tratamiento de los verbos semideponentes entre los gramáticos latinos, que incluye un apartado dedicado a la terminología empleada para designar estos verbos, véase Marchand (2005: 133-150). 
eventos futuros (...). Por su parte, los verbos antedichos se conjugan de este modo: De la segunda conjugación, las formas de indicativo: de presente, soleo soles solet; de imperfecto, solebam solebas solebat; de perfecto, solitus sum; de pluscuamperfecto, solitus eram; de futuro, solebo. Las formas de imperativo: de presente, sole; de futuro, solitus esto. Las formas de optativo: de presente e imperfecto, $<u t>$ solerem; de perfecto, ut solitus sim; de pluscuamperfecto, $u t$ solitus essem; de futuro, ut soleam. Las formas de subjuntivo: de presente, cum soleam; de imperfecto, cum solerem; de perfecto, cum solitus sim; de pluscuamperfecto, cum solitus essem; de futuro, cum solitus ero. Las formas de infinitivo: de presente, solere; de perfecto y de pluscuamperfecto, solitum esse y fuisse; de futuro, solitum ire o soliturum esse. Las formas de participio: de presente, hic solens <etcétera>; de perfecto, hic solitus <etcétera>; de futuro, $<$ hic $>$ soliturus etcétera. Aunque se han conjugado las formas de futuro de este verbo, no se pueden decir, porque uno puede estar acostumbrado a eventos pasados, no a eventos futuros, como ya se ha comentado más arriba'.

Veamos en primer lugar las coincidencias entre los paradigmas del verbo latino y del verbo español. De entrada, hay que poner de manifiesto que no tenemos atestiguado ningún empleo de soleo en futuro. Los gramáticos antiguos, como leemos en el testimonio de Carisio (1), a pesar de que consignan el paradigma completo del verbo, ya subrayan la incompatibilidad de su naturaleza semántica con la expresión de lo venidero. El reiterado argumento del gramático latino para explicar que las formas de futuro de soleo no pueden emplearse se asemeja al que se aduce en el Diccionario de perifrasis verbales, citando a Bertinetto (1997: 213) y a Camus (2004: 529), para justificar la misma restricción del auxiliar soler en español: "no podemos predicar como hábitos los eventos que no han tenido lugar" (García Fernández, 2006: 247).

En cambio, frente a soler, que, según se señala en el Diccionario de perifrasis verbales (2006: 245), carece de las formas no finitas *soler, *soliendo, *solido, su antecesor latino soleo, descartadas las formas de futuro, dispone de los infinitivos, solēre (2), solitum esse (3), solitum fuisse (4), y de los participios, solens (5) y solitus (6-7):

(2) Equidem si quando audio tam defendo quam me scio a te contra iniquos meos solere defendi. (Cicero, Epistulae ad familiares 11, 27, 7) 'Por mi parte, si alguna vez lo oigo te defiendo igual que sé que yo suelo ser defendido por ti contra mis enemigos'. 
(3) In cotidianis autem commentationibus equidem mihi adulescentulus proponere solebam illam exercitationem maxime, qua C. Carbonem nostrum illum inimicum solitum esse uti sciebam. (Cicero, De oratore I 34,154$)$

'Por otra parte, en mis tareas cotidianas de jovencito solía practicar especialmente aquel ejercicio que yo sabía que nuestro ilustre adversario Gayo Carbón *solió usar'.

(4) Hic est enim ille voltus semper idem, quem dicitur Xanthippe praedicare solita in viro suo fuisse Socrate: eodem semper se vidisse exeuntem illum domo et revertentem. (Cicero, Tusculanae disputationes 3, 15, 31)

'Se trata de aquel famoso rostro inalterable que, según dicen, Jantipa * había solido / estuvo acostumbrada a pregonar en su esposo Sócrates: ella siempre lo había visto con la misma expresión al salir él de casa y al regresar'.

(5) Si dixero mendacium, solens meo more fecero. (Plautus, Amphitruo, 198)

'Si digo una mentira, *soliendo / como suelo (yo decir mentiras), lo haré según mi costumbre'.

(6) 'Quantum ingemiscant' inquit 'patres nostri circa moenia Carthaginis bellare soliti, si videant nos, progeniem suam, duos consules consularesque exercitus, in media Italia paventis intra castra'. (Livius, Ab urbe condita 21, 53, 5)

'«Cómo se lamentarían», dijo, «nuestros padres, habituados a batallar en torno a las murallas de Cartago, si nos vieran a nosotros, su descendencia, dos cónsules y sus ejércitos consulares, asustados dentro del campamento en medio de Italia»' .

(7) At Germanico ne solitos quidem et cuicumque nobili debitos honores contigisse. (Tacitus, Annales 3, 5, 1)

'En cambio a Germánico no le habían correspondido siquiera los honores habituales y debidos a cualquier notable'.

Por lo que se refiere a los infinitivos, en (2), solere defendi, en (3), solitum esse uti y en (4) praedicare solita fuisse, aparecen funcionando como auxiliares de otros infinitivos. En (2) y en (3) constituyen los predicados de sendas construcciones completivas AcI (Accusativus cum Infinitivo), de scio y sciebam, respectivamente. La construcción praedicare solita fuisse de (4) desempeña una función predicativa respecto al sujeto de la estructura pasiva personal NcI (Nominatiuvus cum Infinitivo), Xanthippe dicitur, como pone 
de manifiesto la concordancia de solita fuisse con Xanthippe. Volveremos sobre ello a propósito de los usos sintácticos de soleo.

En cuanto a los participios, hay que tratarlos y considerarlos de manera distinta. Las ocurrencias del participio de presente solens son ciertamente testimoniales: se reducen a dos pasajes plautinos, el del contexto (5), donde, sin infinitivo, presenta un uso adjetival predicativo, afín al de la estructura ut soleo que comentaremos en el apartado correspondiente al uso sintáctico como verbo pleno; y otro análogo a $(5)^{10}$, cuya semejanza es tan significativa que lleva a pensar, más bien, en una expresión formular. Después de Plauto, solens es prácticamente inusitado ${ }^{11}$.

La formación participial de perfecto pasivo solitus merece una consideración especial. Los contextos precedentes muestran empleos suyos como auxiliado en las formas perifrásticas de infinitivo de perfecto de los ejemplos (3) y (4); como participio de perfecto propiamente, con el infinitivo auxiliado bellare, en (6) y, asimismo, como adjetivo, en (7).

En este punto, la divergencia entre el español soler y su antecedente latino es relevante. El carácter defectivo del verbo español en cuanto al participio implica que carezca también de formas perfectivas compuestas, -tampoco se conjuga en el perfecto simple- ${ }^{12}$, y se justifica porque el auxiliar soler constituye una perífrasis aspectual de tipo habitual: "la descripción de un evento como habitual obliga a focalizar su desarrollo y es incompatible con la referencia a su conclusión. De ahí que en estos casos se seleccionen siempre formas imperfectas y no sea extraño que allí donde existen, por ejemplo, en español y otras lenguas románicas, las perífrasis de aspecto habitual no admitan flexión de Perfecto, esto es, formas como el participio

10 Cf. Plautus, Casina 869: volo hic, Pardalisca, esse, qui hinc exeat / eum ut ${ }_{*}$. ludibrio habeas. PA. lubens fecero / $*$ * et solens, 'Ahora, Pardalisca, quiero que estés aquí, para tomarle el pelo al primero que salga. PARDALISCA.- Con mucho gusto, lo haré según mi costumbre y como suelo'. El texto del pasaje presenta lagunas, pero el parecido con el empleo de solens en (5) es evidente.

11 Entre los gramáticos latinos ya se encuentran observaciones sobre el bajo índice de empleo del participio de presente solens; Diomedes (s. IV), por ejemplo, en el apartado de su Ars Grammatica dedicado a los verbos que carecen de alguno de los participios, incluye soleo; afirma que nadie usaría el participio de futuro soliturus, y que apenas se usa el de presente (cf. GL I 381, 7).

12 Cf. Diccionario de perifrasis verbales (2006: 245). El DRAE recoge la conjugación completa del verbo soler, incluyendo el participio solido y el pretérito perfecto simple solí. Las ocurrencias del pretérito perfecto simple son anecdóticas (12 ocurrencias) y ninguna de ellas anterior al siglo XIX. Por lo que se refiere a la documentación de solido, no hay ocurrencias del participio documentadas con anterioridad al siglo XV y podemos concluir que se trata de una creación moderna analógica a partir de soler. 
o el perfecto simple" (Camus 2011: 122). En el caso del verbo latino soleo, por el contrario, el hecho de disponer del participio solitus permite que pueda constituir formas perifrásticas perfectivas y aparecer como verbo auxiliado con el auxiliar sum.

En esto radica la discrepancia más notable entre los paradigmas de los dos verbos. Como queda reflejado en el testimonio del gramático Carisio (1), soleo dispone de todas las formas de perfecto para lo pretérito; con la única particularidad, dada la naturaleza semideponente del verbo, de que frente a las formas activas del tema de infectum (8), el perfectum presenta formas pasivas compuestas $(9)^{13}$.

(8) Cicero ita dicere solet, 'Cicerón suele hablar así' Cicero ita dicere solebat, 'Cicerón solía hablar así'

(9) Cicero ita dicere solitus est, 'Cicerón *ha solido / *está solido / * solió / hablar así'

Cicero ita dicere solitus erat, 'Cicerón *había solido / *estaba solido hablar así'

Parece, pues, que el verbo latino soleo no se ve afectado por la restricción típica de las construcciones de aspecto habitual y dicha circunstancia nos interroga sobre la naturaleza aspectual de habitualidad de la perífrasis que constituye como auxiliar (vid. Artigas, en este mismo volumen), atribuida a soleo + INF sin discusión (Pinkster 2015: 212). Sin embargo, para comprender e interpretar correctamente el empleo de las formas de perfecto de soleo, es fundamental tomar en consideración su particular morfología pasiva, así como el alcance aspectual del perfecto latino.

Ya hemos visto que el perfecto latino de la voz pasiva se formaba mediante la unión del participio perfecto pasivo, primitivamente una formación adjetival en *-to-, y el auxiliar sum. La perífrasis así constituida expresaba, en principio, una acción pasada actual y el estado alcanzado como resultado de una acción pasada, al igual que el perfecto de la voz activa. Posteriormente adoptó también el valor aorístico (Blase 1903: 171). Por tanto, el perfecto pasivo latino podía significar pasado actual, estado resultante y pasado aorístico (10). A esto hay que añadir que el participio

\footnotetext{
13 Prisciano, GL II 420, 13 consigna el uso de una forma de perfecto activa solui entre los antiquissimi y cita un ejemplo de Salustio, Hist. 2, 102 soluerat. Nonio, por su parte, da una referencia del historiador Celio Antipatro, Hist. 45 soluerint. Varrón ling. 9, 107 menciona el uso de un perfecto solui por parte de Ennio y de Catón. Sin embargo, estos autores emplean indistintamente solitus sum (Flobert 1975: 499).
} 
de perfecto, dado su origen, presenta, naturalmente, un uso adjetival. De hecho, como resultado de esta ambivalencia, el perfecto pasivo latino acabará convirtiéndose en un presente pasivo y sustituirá la forma sintética (11). Otra consecuencia derivada del mismo hecho es que a veces en la voz pasiva se produce un solapamiento entre el presente y el perfecto resultativo (12).

(10) divisus est, 'ha sido dividido / está dividido / fue dividido'

(11) divisus est = dividitur, 'es dividido'

(12) dividitur = divisus est, 'está dividido'

En el caso de solitus sum, perfecto de soleo, podemos constatar que la posibilidad del perfecto latino de expresar estado resultante, unida al doble sentido de 'habituado' y de 'habitual' (Flobert 1975: 499) de solitus y a su uso adjetival, y, además, la Aktionsart estativa del presente intransitivo soleo, favorecieron muy pronto contextos en los que la distinción aspectual entre el perfecto solitus sum y el presente soleo quedaba neutralizada. En (13), solitus est, frente a non solet, expresa claramente un estado actual alcanzado.

(13) Quid, tu idem mihi vis fieri, quod erus consuevit tibi? / Si ille te comprimere solitus $<\mathbf{t}>$, hic noster nos non solet. (Plautus, Rudens 1075)

' Ah, tú quieres que se me haga lo mismo que tu amo tiene por costumbre hacerte a ti! Si el tuyo está acostumbrado a darte..., el nuestro no acostumbra con nosotros'.

Junto a ello, sin embargo, encontramos empleos del perfecto solitus est con valor aorístico, como en (14a) y (15a), que son los que entrarían en contradicción con la naturaleza de aspecto habitual.

(14) a. Post ob uirtutem ero Amphitruoni patera donata aureast, / qui Pterela potitare rex est solitus. (Plautus, Amphitruo 261)

'Después, por su valor, a mi amo Anfitrión se le donó en recompensa la copa de oro en la que *solió / acostumbró a beber habitualmente el rey Pterelao'.

b. Nunc tibi hanc pateram, quae dono mi illi ob uirtutem data est, / Pterela rex qui potitauit, quem ego mea occidi manu, / Alcumena, tibi condono. (Plautus, Amphitruo 534-536)

'Toma esta copa que me (aparte, 'le') fue donada en recompensa al valor, en la que bebió habitualmente el rey Pterelao y al que yo maté con mis propias manos; ea, te la regalo'. 
(15) a. P. Crassum ... laudandum puto, quod ... solitus est ei [P. Scaevolae fratri] persaepe dicere neque illum in iure civili satis [illi arti] facere posse, nisi dicendi copiam adsumpsisset. (Cicero, De oratore I 170) 'A Publio Craso lo considero digno de alabanza porque *solió / acostumbró a decirle en muchísimas ocasiones a su hermano Publio Escévola que él no podría ejercer satisfactoriamente el derecho civil hasta haber adquirido suficiente elocuencia'.

b. Sed, ut solebat C. Lucilius saepe dicere, homo tibi subiratus... (Cicero, De oratore I 72)

'Pero, como solía decir a menudo Gayo Lucilio, un hombre que está molesto contigo...'.

Un examen somero de traducciones del pasaje (14a) pone en evidencia la dificultad que plantea el perfecto latino solitus est. Por poner un ejemplo, tomemos la siguiente: 'Después por su valor mi amo Anfitrión recibió como regalo la copa de oro en la que solía beber el rey Pterelao" ${ }^{14}$. ¿Es eso realmente lo que el esclavo Sosia quiere decir o, mejor, lo que Plauto quiere que diga el esclavo Sosia cuando lo pone en boca suya? ¿Se trata simplemente de marcar el hábito o la pluriocurrencia del evento 'beber en esa copa por parte del rey Pterelao'? ¿Qué diferencia supondría una forma de imperfecto solebat frente al perfecto solitus est? De hecho, en latín, al igual que en español, el perfecto, dado que proporciona una visión completa de una situación de pasado, aparece con referencias explícitas al número de ocasiones, mientras que el hábito, o la pluriocurrencia, sin referencia explícita al número de veces, se indica con el imperfecto. El latín proporciona ejemplos de este contraste con todo tipo de verbos, estativos, dinámicos y atélicos, dinámicos y télicos o puntuales (Haverling 2010: 441-442).

También es importante señalar que en latín la pluriocurrencia no se expresa necesariamente mediante la marca morfológica del imperfecto. El latín dispone de sufijos verbales específicos para indicarla. El infinitivo auxiliado potitare que aparece en el pasaje del Anfitrión de Plauto (14a) presenta, precisamente, un sufijo iterativo que le aporta el rasgo semántico de pluriocurrencia. Estos verbos iterativos se pueden encontrar en imperfecto sin referencia al número de veces, pero también en perfecto. Haverling (2010: 443-444) compara el empleo del frecuentativo del verbo venio, ventito 'venir, ir habitualmente', en dos pasajes; en uno se encuentra usado en imperfecto, 
ventitabat, $\mathrm{y}$, en el otro, en perfecto, ventitavit. La conclusión, a partir de los ejemplos, es que la diferencia entre la utilización del imperfecto o del perfecto estriba en marcar el evento pasado como contextual, con el imperfecto, o como una visión completa, en primer plano, con el perfecto. El rasgo de aspecto habitual, así pues, no lo aporta el imperfecto sino el sufijo iterativo del verbo, que, por otra parte, es compatible con la morfología flexiva del perfecto.

Volviendo al pasaje plautino (14a), si en la perífrasis potitare est solitus, el sufijo iterativo del infinitivo auxiliado potitare ya significa la pluriocurrencia del evento 'beber en la copa de oro', ¿debemos considerar redundante el rol de solitus est por lo que se refiere a la Aktionsart? De hecho, en la misma obra, unos versos más adelante, el dios Júpiter, bajo la apariencia de Anfitrión, le regala a su esposa Alcmena la famosa copa del rey Pterelao. La información que le proporciona sobre el origen del regalo es la misma que ha dado anteriormente el esclavo Sosia y Júpiter la reproduce prácticamente con las mismas palabras (14b), aunque con una diferencia significativa: en lugar de la perífrasis potitare est solitus emplea el perfecto del auxiliado, potitavit.

Gerd Haverling (2010: 444) afirma que, además de la sufijación, el latín dispone del verbo soleo para expresar de manera específica el aspecto habitual. Constata que el uso de los tiempos de pasado de soleo constituye otro ejemplo de que la pluriocurrencia no es un rasgo marcado por la morfología flexiva del imperfecto o del perfecto, sino que está en la semántica del verbo. El empleo del perfecto o del imperfecto lo que hace es denotar el fuerte énfasis que el latín clásico pone en el contraste entre visión completa en primer plano de evento de pasado o descripción contextual de evento pasado, como queda de manifiesto al contrastar el perfecto solitus est de (15a) y el imperfecto solebat de (15b).

En (14a), la morfología de perfecto del auxiliar solitus est presenta el macroevento iterativo potitare, 'beber habitualmente', confinado en el pasado entre los límites de la vida del rey Pterelao. Esto, sin embargo, también lo indica la forma de perfecto potitavit de (14b), porque, en realidad, la pluriocurrencia está en el morfema iterativo del verbo, no en la semántica de solitus est. La semántica de solitus est, en consonancia con la explicación etimológica propuesta, más bien supone la atribución del evento iterativo 'beber habitualmente en la copa de oro' al sujeto 'rey Pterelao', como algo propio o característico de él mientras vivió. De igual manera, en (15a), mediante solitus est, se atribuye a Publio Craso como rasgo propio, digno de alabanza, la insistencia en la formación retórica de su hermano Publio Escévola. No parece, por tanto, que la expresión del aspecto habitual, equivalente a la expresión de eventos habituales que se materializa con los 
sufijos iterativos, sea, en primera instancia, la función que debamos asignar a solitus est.

En cualquier caso, en el latín tardío se constata un claro retroceso en el empleo del perfecto solitus est, debido, probablemente, sobre todo a la ambivalencia funcional y semántica del participio solitus. Son normales los ejemplos con valor de presente 'es habitual' (16a) y sufre la competencia de solebat en la narración de eventos pasados completos (16b), como señala Haverling (2010: 489). Todo ello conduce a una reestructuración en el empleo de solitus est y acabaría por explicar, seguramente, el carácter defectivo del paradigma temporal del auxiliar español soler.

(16) a. Et in hoc loco error est solitus. (Hieronymus, in Osee 2, 9 lin. 145) 'Aquí el error es habitual'.

b. Socrates quoque dicere solebat omnes in eo, quod scirent, satis esse eloquentes (Iulius Victor, Ars rhetorica p. 3 lin. 4)

'Sócrates también solía decir que todos los hombres hablan con elocuencia suficiente de aquello que saben’.

\subsection{UsOS SINTÁCTICOS}

Desde el punto de vista sintáctico, soleo muestra siempre un comportamiento intransitivo y, por lo general, un funcionamiento como verbo auxiliar (Pinkster 2015: 212). Es significativo, sin embargo, el elevado índice de ejemplos en los que el infinitivo se encuentra elidido. Normalmente, cuando se da el caso, el infinitivo se puede recuperar sin dificultad del contexto. Ahora bien, soleo también presenta un uso absoluto impersonal, a veces con un pronombre neutro como sujeto, en estructuras relativas y modales, que manifiesta un claro empleo como verbo léxico pleno, en el que aflora el valor semántico prototípico propuesto a partir de su etimología.

\subsubsection{Verbo auxiliar}

En principio, soleo, con un infinitivo como segundo argumento, reúne los requisitos que Pinkster (2015:210-215) establece como propios de los verbos auxiliares latinos. Además de soleo, calificado como auxiliar habitual, se consideran auxiliares inequívocos los modales debeo 'deber', possum 'poder, ser capaz, ser posible', queo 'poder, ser capaz' y пеqueo 'no poder, no ser capaz'.

En tanto que auxiliar, soleo únicamente admite como segundo argumento infinitivos presente de otros verbos; no permite ni nombres, ni frases 
completivas. También hallamos algún contexto en el que el segundo argumento está representado por possum 'poder', funcionando como verbo léxico pleno (17) o como auxiliar modal en combinación con otro infinitivo como segundo argumento, constituyendo un encadenamiento perifrástico (18).

(17) Necessitas plus posse quam pietas solet. (Seneca, Troades 578) 'La necesidad suele poder más que la piedad'.

(18) Solebat indignatio vestra convicia nostra ferre non posse... (Quintilianus (pseudo), Declamationes maiores, 19,6) 'Vuestra indignación solía no poder soportar nuestros encuentros..'.

Generalmente el sujeto del infinitivo no está explícito, pero es el mismo que el del auxiliar soleo, como revela la concordancia de caso, género y número que presentan los eventuales predicados nominales asociados al infinitivo auxiliado. Así queda ilustrado en (19) con el adjetivo predicativo primus; en (20a), con el sustantivo gladiator, predicativo del sujeto M. Antonius, argumento paciente de appellari solet; o, en (20b), con el sintagma nominal consularem scurram, predicativo del acusativo sujeto eum de la completiva AcI, cuyo predicado es una perífrasis verbal constituida por el infinitivo perfecto solitum (esse) y el infinitivo auxiliado de presente pasivo appellari.

(19) Mos est Syracusis ut, si qua de re ad senatum refertur, dicat sententiam qui velit; nominatim nemo rogatur, et tamen, ut quisque aetate et honore antecedit ita primus solet sua sponte dicere. (Cicero, In C. Verrem II $4,64)$

'Es costumbre en Siracusa, si se consulta sobre algún asunto al Senado, que quien quiera diga su opinión; no se le pide a nadie nominalmente, $\mathrm{y}$, sin embargo, según cada cual precede en edad y condición, suele hablar el primero espontáneamente..'

(20) a. Quem gladiatorem non ita appellavi ut interdum etiam M. Antonius gladiator appellari solet, sed ut appellant ei qui plane et Latine loquuntur. (Cicero, Philippicae VII 17)

' $\mathrm{Y}$, a éste, no lo he llamado gladiador tal como suele ser llamado gladiador a veces también M. Antonio, sino como lo llaman los que hablan claro y en latín'.

b. Quis item nescit consularem eum (Ciceronem) scurram ab inimicis appellari solitum? (Macrobius, Saturnalia II 4, 64)

¿QQuién ignora que él *solió / acostumbró a ser llamado bufón consular por sus enemigos?’ 
(21) Quod si esset beneficium, numquam qui illum interfecerunt a quo erant conservati, quos tu ipse clarissimos viros soles appellare, tantam essent gloriam consecuti. (Cicero, Philippicae II 5)

'Si esto fuera un favor, nunca hubieran conseguido tanta gloria los que mataron a aquel que los había salvado, a quienes tú mismo sueles llamar hombres ilustrísimos'.

Por tanto, el auxiliar soleo y el verbo pleno en infinitivo forman una perífrasis verbal y las propiedades de esta perífrasis y las estructuras sintácticas posibles son las propias del verbo pleno.

Una prueba decisiva para determinar la condición de perífrasis verbal es la pasivización: la conversión a pasiva de una perífrasis promueve el objeto o tema de la predicación transitiva a sujeto de la construcción. En contextos precedentes hemos encontrado ejemplos de perífrasis constituidas por soleo y un infinitivo pasivo: en (2), me solere defendi ('que yo suelo ser defendido'), con el complemento agente explícito a te ('por ti'); en (20a), M. Antonius appellari solet ('M. Antonio suele ser llamado') con el predicativo gladiator ('gladiador'); y en (20b), eum appellari solitum ('que él acostumbró a ser llamado'), con el predicativo scurram consularem ('bufón consular') y el complemento agente ab inimicis ('por sus enemigos'). Con esta referencia y como confirmación de la naturaleza auxiliar del verbo latino soleo en estas construcciones, el ejemplo (21) proporciona un contexto en el que, si cambiamos la predicación transitiva de la perífrasis soles appellare modificando la voz del infinitivo, el acusativo quos, tema de la frase transitiva se transforma en el nominativo qui, haciendo las veces de sujeto, y el auxiliar soleo asume las propiedades morfosemánticas restantes de la nueva predicación solent appellari:

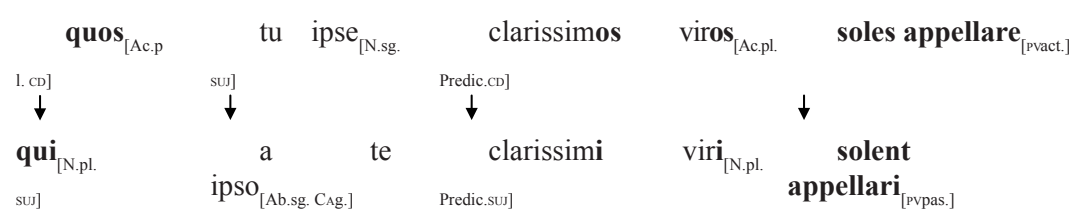

Otra característica que comparten los auxiliares latinos, y con ellos nuestro verbo, es que no presentan restricciones en cuanto a los infinitivos a los que pueden acompañar. Así, soleo + INF puede seleccionar sujetos animados, como elephantum en (22) o, inanimados, como domus en (23). Puede combinarse con infinitivos de verbos dinámicos, como agere en (24), y estativos, como esse en (22) y en (25). Puede ir con infinitivos que denoten control por parte del sujeto, (24) y (25), y no control, (22) y (23). 
(22) †Auditavi saepe hoc uolgo dicier† / solere elephantum gravidam perpetuos decem / esse annos; eius ex semine haec certost fames, / nam iam compluris annos utero haeret meo. (Plautus, Stichus 168)

'A menudo he oído repetir a la gente que las elefantas suelen estar preñadas durante diez años seguidos; seguro que mi hambre es de su misma raza, pues ya lleva muchos años alojada en mis entrañas'.

(23) Ampla domus dedecori saepe domino fit, si est in ea solitudo, et maxime, si aliquando alio domino solita est frequentari. (Cicero, $D e$ officiis 1, 139)

'Una casa grande, si está desocupada, a menudo es causa de deshonor para su amo y, sobre todo, si anteriormente, cuando era de otro, *solió / acostumbró a ser frecuentada'.

(24) Nil ego in occulto agere soleo. Meus ut animust eloquar. (Plautus, Trinummus 712)

'Yo no suelo hacer nada a escondidas. Te diré lo que pienso'.

... quia ruri crebro esse soleo. (Terentius, Hecyra 215)

'... porque suelo estar las más de las veces en el campo'.

Ya hemos comentado que son numerosos los pasajes en los que el infinitivo unido a soleo se encuentra elidido porque es claramente deducible del contexto. Así, en (26) es fácil sobreentender para el auxiliar solent un infinitivo facere a partir de la forma fecit precedente. En el enunciado de (27) quo saturi solent ('adonde suelen los que tienen la barriga llena') también se deduce un infinitivo ire del contexto inmediatamente anterior. La subordinada de relativo, además, constituye un giro eufemístico para referirse a la letrina o a la acción de defecar, un ámbito que abona los sobreentendidos. Asimismo, parece que cabe atribuir a la interdicción lingüística la omisión convencional del infinitivo futuere 'joder' de (28), en uso absoluto (futuere cum viris suis), y de (29), en uso transitivo (futuere Maeciliam). Esta es la interpretación que da Pinkster (2015: 211-112), al menos, para el ejemplo de Catulo (29), avalándola con un pasaje horaciano que presentaría el mismo fenómeno, pero con el auxiliar possum en lugar de soleo $^{15}$.

15 Horatius, Epodi 12, 15: Inachia langues minus ac me; / Inachiam ter nocte potes, mihi semper ad unum / mollis opus ('Con Inaquia te agotas menos que conmigo, si se trata de Inaquia tres veces puedes por noche, pero a mí, siempre te me quedas sin fuerza a la primera'.). Pinkster traduce el duo ... solebant Maeciliam catuliano (29) por 'two men used to fuck Maecilia' (2015: 211) y el Inachiam ter nocte potes de Horacio como 'You can fuck Inachia three times a night' (2015: 212). 
(26) Hic senex si quid clam uxorem suo animo fecit volup, / neque novom neque mirum fecit nec secus quam alii solent. (Plautus, Asinaria 942) 'Este viejo, si echó una cana al aire a espaldas de su mujer, no hizo nada nuevo ni raro ni diferente a lo que suelen (hacer) los demás'.

(27) Rogant me servi quo eam: dico me ire quo saturi solent. (Plautus, Curculio 362)

'Los esclavos me preguntan adónde voy. Les digo que voy adonde suelen (ir) los que tienen la barriga llena'.

(28) Viris cum suis praedicant nos solere, / suas paelices esse aiunt, eunt depressum. (Plautus, Cistellaria 38)

'Pregonan a los cuatro vientos que nosotras solemos... / tenemos trato con sus maridos: dicen que somos sus pelanduscas; van a hundirnos'.

(29) Consule Pompeio primum duo, Cinna, solebant / Maeciliam; facto consule nunc iterum / manserunt duo, sed creverunt milia in unum / singula. (Catullus, Carmina 113, 1-2)

'Cuando el primer consulado de Pompeyo, eran dos, Cina, los que solían... / trataban a Mecilia; ahora que es cónsul por segunda vez, los dos siguen, pero se han multiplicado por mil'.

Ciertamente la elipsis eufemística es un recurso usado a menudo en el ámbito sexual. Ahora bien, en los pasajes (28) y (29), la omisión de un infinitivo que no se puede recuperar del contexto inmediato, porque justamente lo que se busca es la ambigüedad y la imprecisión, es muy significativa por lo que respecta al funcionamiento sintáctico de soleo en ellos. La lectura literal de viris cum suis nos solere de (28), 'que nosotras solemos (eso ¿?) con sus maridos', y de duo solebant Maeciliam de (29), 'dos hombres solían (eso ¿?) en relación con Mecilia' nos lleva a tomar en consideración el empleo de soleo como verbo pleno.

\subsubsection{Verbo pleno}

Fernández de Castro (1999: 36) asegura que "el derivado verbal de una perífrasis no acepta fácilmente ser referido por indicadores de función nominal autónoma, ya sean pronombres, «proadverbios» o «proadjetivos» del tipo así, cómo, etc.; el elemento preferido para rescatar su valor funcional es el verbo vicario o "proverbo» hacer".

Esto no parece que se pueda aplicar a soleo, pues hay ejemplos claros en los que el verbo latino se encuentra acompañado por pronombres neutros y sin el infinitivo hacer: 
(30) Vola curriculo. PA. istuc marinus passer per circum solet. (Plautus, Persa 199)

'Vuela corriendo. Pegnio.-Esto es lo que suele (hacer) el avestruz por el circo'.

(31) Tu quod saepe soles, nostro laetabere casu, / Galle... (Propertius, Elegiae I 13, 1)

'Tú, cosa que sueles (hacer) a menudo, Galo, te alegrarás de mi caída en desgracia..'.

(32) (Vindex) risit, nam solet hoc... (Martialis, Epigrammata IX 44, 3) '(Víndice) se rio, pues suele (hacer) esto...'.

(33) Mihi quidem edepol insignite factast magna iniuria: / duobus nupsi, neuter fecit quod novae nuptae solet. (Plautus, Casina 1011)

'Por Pólux, a mí sí que se me ha hecho hoy una buena faena y de las gordas. Me he casado con dos hombres y ninguno me ha hecho lo que se suele (hacer) a una recién casada'.

(34) Simul, id quod in tali re solet, alii portenta atque prodigia nuntiabant, alii conventus fieri, arma portari, Capuae atque in Apulia servile bellum moveri. (Sallustius, De coniuratione Catilinae 30,2)

'Al mismo tiempo, lo que se suele (hacer) / es típico en tal circunstancia, unos anunciaban portentos y prodigios, otros que había reuniones, que se transportaban armas, que en Capua y en Apulia se preparaba una revuelta de esclavos'.

En los tres primeros contextos el estado de cosas focalizado al que se refieren los pronombres se presenta, a través de soleo, como característico de su sujeto: el 'volar corriendo', istuc, de (30) es típico del avestruz; el 'alegrarse por la desgracia del poeta' de (31), quod, es típico de Galo, como lo es, de Víndice, el 'reírse', hoc, en (32). Por otra parte, en (33), el pronombre quod es el sujeto impersonal de solet y alude eufemísticamente a la 'cosa típica de una recién casada', es decir, a su desfloración. En el ejemplo de Salustio (34), nuevamente, el relativo quod representa el sujeto impersonal de una forma verbal solet que define el 'estado de cosas' como 'típico, normal' en un contexto prebélico ${ }^{16}$.

\footnotetext{
16 Cf. Antelo (2018: 13), a propósito del ejemplo quodque in extremis solet (Seneca, Oedipus 58).
} 
De manera semejante, el latino soleo se encuentra usado sin infinitivo, modificado por los adverbios ita o sic 'así', para definir al sujeto por su manera propia de actuar:

(35) Men. non potuisti magi' per tempus mi advenire quam advenis. / PE. Ita ego soleo: commoditatis omnis articulos scio. (Plautus, Menaechmi 140)

'MeNECMo I.- No has podido llegar en un momento más oportuno para mí. Escobilla.-Así suelo (hacerlo) yo: me sé todos los recodos de la oportunidad'.

(36) GN. sex ego te totos, Parmeno, hos mensis quietum reddam / ne sursum $\mathrm{d}<$ eo $>$ rsum cursites neve usque ad lucem vigiles. / Ecquid beo te? PA. Men? Papae. GN. Sic soleo amicos. PA. laudo. (Terentius, Eunuchus 279)

GNATÓN.- Yo, Parmenón, haré que de aquí en adelante puedas descansar durante seis meses enteros, sin tener que andar corriendo de acá para allá ni velar hasta el alba. ¿Qué te parece?, ¿te hago feliz? PARMENÓN.¿A mí? ¡Ole, ole! GnATón.-Así suelo (hacer) yo para con mis amigos. PARMENÓN.- Te felicito.

En el pasaje plautino (35), Menecmo se alegra de la oportuna llegada de su esclavo y este la justifica atribuyéndose como rasgo propio el don de la oportunidad: 'yo me caracterizo por ser así'. Del mismo modo, el parásito Gnatón, de la comedia de Terencio $(36)^{17}$, se caracteriza a sí mismo como personaje benefactor con los amigos.

Es importante señalar que tales usos de soleo son tempranos: buena parte de los ejemplos aducidos pertenecen a Plauto, comediógrafo de época arcaica. Asimismo, se encuentran muy pronto casos de anáfora cero del infinitivo con soleo, en oraciones comparativas, como las que analiza Manfredini (2016: 262-275) a propósito de possum. Se trata de enunciados ya de por sí caracterizadores, en los que soleo presenta la acepción 'es propio, habitual, normal' que hemos postulado como prototípica a partir de su etimología:

(37) Haec ego non rideo, quamvis tu rideas, sed de re severissima tecum, ut soleo, iocor. (Cicero, Epistulae ad familiares 7, 11, 2) 
'Yo no me estoy burlando, por más que tú te rías, sino que, como suelo (hacer) / tengo por costumbre, bromeo contigo sobre asuntos serios'.

(38) Nunc venio ad iocationes tuas, quoniam tu secundum Oenomaum Attii, non, $\boldsymbol{u} \boldsymbol{t}$ olim solebat, Atellanam, sed, $\boldsymbol{u} \boldsymbol{t}$ nunc fit, mimum introduxisti. (Cicero, Epistulae ad familiares 9, 16, 7)

'Y ahora llego a tus bromas, puesto que después del Enomao de Accio no presentaste una atelana, como antes era costumbre, sino un mimo, como se hace ahora'.

(39) Clamor inde oppidanorum mixtus muliebri puerilique ploratu ad terrorem, $\boldsymbol{u} \boldsymbol{t}$ solet, primo ortus et Romanis auxit animum. (Livius, $A b$ urbe condita, 2, 33, 8)

'El clamor de los ciudadanos mezclado con el llanto de mujeres y niños que se produjo inmediatamente ante el terror, como es normal, no solo levantó el ánimo a los romanos..'.

Cicerón con ut soleo, en (37), quiere significar que, bromeando sobre cosas serias con su amigo, actúa en consonancia con el comportamiento que le es propio, que lo caracteriza. En el pasaje siguiente (38), el solebat impersonal del enunciado ut olim solebat contrapone la práctica común característica de una época anterior con la actual. Finalmente, en (39) con ut solet se caracteriza como algo habitual el hecho de que ante una situación de terror la población reaccione gritando y llorando. Así pues, los ejemplos precedentes de soleo sin infinitivo documentados desde la latinidad arcaica, como decíamos, creemos que ilustran un empleo como verbo pleno y que avalan la hipótesis etimológica de considerarlo un verbo estativo denominativo con el valor prototípico de 'ser propio, ser costumbre'.

\section{RECAPITULACIÓN: SOLER A LA LUZ DE SOLEO}

El uso semiauxiliar que Olbertz (1998: 128) propone para el español soler puede examinarse en relación con el empleo como verbo pleno señalado para el latín soleo en el apartado anterior.

(40) ...cumplir el mismo ritual erótico-romántico que solía con las chicas de mi edad.

(41) En vez de tachar escuetamente, como solía, el nombre, número y señas del desaparecido. 
El ejemplo (40) de Olbertz sería equiparable a (26) y (27), casos en los que el infinitivo se puede deducir del contexto inmediato. En cuanto a como solía de (42), nos parece un uso análogo al ut soleo de (37). Ciertamente, Olbertz ya lo admite, el número de ejemplos del español que ofrece para confirmar la semiauxiliaridad de soler es reducido. Habría que añadir algún caso más que proporciona Casado Velarde (1983: 74) y un pasaje del Libro de la Caza de Juan Manuel recogido por Yllera (1980: 200), con un testimonio de soler + que + IND. Aunque en conjunto no parece documentación suficiente como para constituir evidencia de un uso semiauxiliar para el español soler, el precedente de los empleos plenos del verbo latino soleo vendría a apoyar tal propuesta y representaría un punto de partida para trazar los distintos estadios del proceso de gramaticalización del auxiliar soler y de la construcción que conforma con un infinitivo.

Hemos visto que la hipótesis etimológica adoptada para el verbo latino soleo nos autoriza a categorizarlo como presente estativo denominativo y a proponer la acepción 'ser de uno, ser propio, ser normal, ser costumbre' como prototípica. En el uso de soleo como verbo pleno, atestiguado desde época temprana, este es el valor que entra en consideración. La interpretación, por tanto, de la construcción que soleo, como auxiliar, constituye con un infinitivo pasa por tener en cuenta esta etimología y su "persistencia" semántica en el nuevo complejo. Igualmente, en una descripción rigurosa del proceso de gramaticalización de la perífrasis del español soler + INF las trazas semánticas de soleo en el auxiliar soler no pueden ser ignoradas.

Por otra parte, el examen de la singularidad morfológica de soleo en contraste con el paradigma defectivo del español soler proporciona datos interesantes para dibujar con más precisión el recorrido seguido por la perífrasis del español soler + INF desde una perspectiva aspectual. Hoy por hoy, hay acuerdo en considerar que esta construcción representa la subvariante habitual dentro del aspecto imperfectivo y que la conjugación de soler, a consecuencia de su distribución exclusiva como auxiliar en esta perífrasis, es defectiva y solo presenta formas imperfectivas (Camus 2004: 511). Como se ha expuesto, el paradigma del verbo latino soleo, en cambio, dispone de formas de perfecto y su uso con valor aorístico entra en contradicción con la restricción morfológica del auxiliar español soler. Con todo, aquí el perfecto solitus sum también exhibe su singularidad en tanto que semideponente y, para evaluar el uso de las formas de perfecto, resulta imprescindible poner atención en su morfología pasiva, así como en el alcance aspectual del perfecto latino (Artigas-Cabré: en prensa). En la combinación de estos dos factores probablemente halla su explicación el carácter defectivo del paradigma temporal del auxiliar español soler. 


\section{REFERENCIAS BIBLIOGRÁFICAS}

\section{BASES DE DATOS}

CDL: Cross Database Searchtool, Brepolis Library of Latin Texts Series A - B, Turnhout, Brepols http://www.brepolis.net

CoRDE: Real Academia Española, Corpus diacrónico del español http://www.rae.es

DLD: Database of Latin Dictionaries, Turnhout, Brepols http://www.brepolis.net

ThLL (1900 - ): Thesaurus linguae Latinae, Teubner, Stuttgart - Leipzig (electronic resource CD, K.G. Saur - Walter de Gruyter).

\section{BIBLIOGRAFÍA}

Antelo Reinoso, Ignacio. 2018. Soleo en Séneca: frecuencia y funcionalidad en las tragedias. Stylos 27: 7-20.

Artigas, Esther y Laura Cabré. (en prensa). ¿Acostumbraron los antiguos dezirlo así? Perfectividad y aspecto habitual en latín". En Garachana, Mar (ed.). La evolución de las perifrasis verbales en español. Una aproximación desde la Gramática de construcciones diacrónica. Bern: Peter Lang.

Bertinetto, Pier Marco. 1997. Il dominio tempo-aspettuale: Demarcazioni, intersezioni, contrasti. Torino: Rosenberg \& Sellier.

Blase, HeinRICH. 1903. Historische Grammatik der lateinischen Sprache. Syntax des einfachen Satzes (Tempora und modi; Genera verbi). Leipzig: Teubner.

Camus, Bruno. 2004. Perífrasis verbales y expresión del aspecto en español. En Luis García Fernández y Bruno Camus (eds.). El pretérito imperfecto. Madrid: Gredos, pp. 511-573. 2011. Restricciones aspectuales y la perífrasis soler + infinitivo. En Juan Cuartero Otal, Luis García Fernández y Carsten Sinner (eds.). Estudios sobre perifrasis y aspecto. München: Peniope, pp. 120-138.

Casado Velarde, Manuel. 1983. El verbo soler y los modales. Boletín de la Real Academia Española LXIII 1: 67-76.

FernÁNDez de CAStro, Félix. 1999. Las perífrasis verbales en el español actual. Madrid: Gredos.

Flobert, Pierre. 1975. Les verbes déponents latins des Origines à Charlemagne, Paris: Les Belles Lettres.

Garachana Camarero, Mar. 2017. Los límites de una categoría híbrida. Las perífrasis verbales. En Garachana, M. (ed.). La gramática en la diacronía. La evolución de las perifrasis verbales modales en español, pp. 35-80. Madrid - Frankfurt: Iberoamericana Vervuert.

García Fernández, Luis (dir.). 2006. Diccionario de perifrasis verbales. Madrid: Gredos.

García Trabazo, José Virgilio. 2004. Sobre el reflejo de la Aktionsart 'estativa' indoeuropea en hitita y latín. En $\mathrm{M}^{\mathrm{a}}$ Teresa Amado, Eva $\mathrm{M}^{\mathrm{a}}$ Castro, Cecilia Criado, Amelia Pereiro y Concepción Cabrillana (coords.). Iucundi acti labores. Estudios en homenaje a Dulce Estefanía Álvarez, pp. 103-112. Santiago de Compostela: Universidade de Santiago, Servicio de Publicaciones.

GL = KeIL, HeInRICh. 1855-1880. Grammatici Latini. Leipzig: Teubner.

Gómez ToRrego, LeONARDo. 1999. Los verbos auxiliares. Las perífrasis verbales de infinitivo. En Ignacio Bosque y Violeta Demonte (eds.). Gramática descriptiva de la lengua española, pp. 3323-3388. Madrid: Espasa Calpe. 
Grienberger, TheOdor von. 1900. Untersuchungen zur gotischen Wortkunde. Wien: In Commission bei Carl Gerold's Sohn.

HAMP, Eric P. 1985. Derivatives of *sue in latin. 1. soleō „be wont“. Živa Antika 35. 16.

Haverling, Gerd V. M. 2010. Actionality, tense and viewpont. En Philip Baldi y Pierluigi Cuzzolin (eds.). New Perspectives on Historical Latin Syntax 2. Constituent Syntax: Adverbial Phrases, Adverbs, Mood, Tense, pp. 277-523. Berlin-New York: De Gruyter Mouton.

Hopper, Paul J. 1991. On some Principles of Grammaticalization. En Elizabeth Closs Traugott y Bernd Heine (eds.). Approaches to grammaticalization. Volume 1, pp. 17-35. Amsterdam-Philadelphia: John Benjamins Publishing Company.

IEW $=2007$. Indo-European Language Association. Proto-Indo-European Etymological Dictionary. A revised edition of Julius Pokorny's Indogermanisches Etymologisches Wörterbuch, http://dnghu.org/.

Lehmann, Winfred Philipp. 1986. A Gothic Etymological Dictionary. Leiden: E. J. Brill.

Leumann, Manu. 19775. Lateinische Laut- und Formenlehre. München: C. H. Beck'sche Verlagsbuchhandlung.

LIPP II = Dunkel, George E. 2014. Lexikon der indogermanischen Partikeln und Pronominalstämme. Heidelberg: Universitätsverlag Winter.

LIV $^{2}=$ Rix, Helmut (ed.). 2001. Lexikon der Indogermanischen Verben. Wiesbaden: Ludwig Reichert Verlag.

MANFREDINI, AdRIANA. 2016. Auxiliaries within comparative clauses: some remarks concerning their syntax and grammatical description: Descriptive and Historical Accounts for the Latin Language. En Paolo Poccetti (ed.). Latinitatis rationes, pp. 262-276. Berlin-Boston: Walter de Gruyter.

Marchand, Diane. 2005. Les verbes semi-déponents chez les grammairiens latins. Lalies: actes des sessions de linguistique et de littérature, 26: 133-150.

Olbertz, Hella. 1998. Verbal Periphrases in a Functional Grammar of Spanish. Berlin-New York: Mouton de Gruyter.

Pinkster, Harm. 2015. The Oxford Latin Syntax. Volume 1: The simple clause. Oxford: Oxford University Press.

Poucet, JACQues. 1966. L'origine sabine de la commutatio du - $d$ - en -l-, un mythe linguistique? L'antiquité classique 35, 1: 140-148.

Squartini, Mario. 1998. Verbal Periphrases in Romance. Aspect, Actionality, and Grammaticalization. Berlin-New York: Mouton de Gruyter.

Traugott, Elizabeth Closs y Graeme Trousdale. 2013. Constructionalization and Constructional Changes. Oxford: Oxford University Press.

VaAn, Michiel De. 2008. Etimological Dictionary of Latin and other Italic Languages. Leiden: Brill.

VERNET, MARIONA. 2008. La segona conjugació verbal llatina: estudi etimologic i comparatiu sobre l'origen protoindoeuropeu de la formació dels seus temes verbals. Barcelona: PPU.

YlLeRA, Alicia. 1980. Sintaxis histórica del verbo español: las perifrasis medievales. Zaragoza: Universidad de Zaragoza. 